Int. J. Dev. Biol. 60: 53-56 (2016)

doi: $10.1387 / \mathrm{ijdb} .150307 \mathrm{rs}$

\title{
Nucleolar protein 4-like has a complex expression pattern in zebrafish embryos
}

\author{
SUPRIYA BORAH ${ }^{1,2}$, PRAVEEN BARRODIA ${ }^{1,2}$ and RAJEEB K. SWAIN ${ }^{*, 1}$ \\ ${ }^{1}$ Institute of Life Sciences, Nalco Square, Chandrasekhar Pur, Bhubaneswar, Odisha, India and \\ ${ }^{2}$ Manipal University, Manipal, Karnataka, India
}

\begin{abstract}
The nucleolar protein 4-like (NOL4L) gene is present on chromosome 20 (20q11.21) in humans. Parts of this gene have been shown to fuse with RUNX1 and PAX5 in acute myeloid leukemia and acute lymphoblastic leukemia, respectively. The normal function of NOL4L in humans and other organisms is not well understood. The expression patterns and functions of NOL4L homologs during vertebrate development have not been reported. We sought to address these questions by studying the expression pattern of zebrafish nol4/during embryogenesis. Our data show that Znol4I mRNA is expressed in multiple organs in zebrafish embryos. The sites of expression include parts of the brain, spinal cord, pronephros, hematopoietic cells and gut.
\end{abstract}

KEY WORDS: diencephalon, telencephalon, trigeminal ganglia, spinal cord neuron, pronephros

\section{NOL4L proteins are highly conserved among vertebrates}

NOL4L (also known as C20ORF112) was reported as a gene that fuses with PAX5 and RUNX1 due to chromosomal translocation in humans. These fusion proteins have been detected in acute lymphoblastic leukemia and acute myeloid leukemia patients (An et al., 2008; Guastadisegni et al., 2010; Kawamata et al., 2008). There are multiple isoforms of NOL4L. Delta blast was carried out with the longest isoform to identify the orthologs of this protein in other organisms. NOL4Lorthologs are present in most vertebrates and are well conserved in human, mouse, chicken, Xenopus and zebrafish. Znol4la located on chromosome 8 and Znol4lb located on chromosome 23 may be paralogs. Sequence alignment of longest form of NOL4L proteins from above five species shows that, there is a high degree of conservation among these proteins (Fig. 1). We have focused on Znol4lb in this study, which shows slightly higher identity with human NOL4L.

\section{Temporal expression pattern of Znol4Ib}

Two different primer pairs were used to study the temporal expression pattern of Znol4lb mRNA during zebrafish development (Fig. 2A). Primer pair-1 can recognize all the transcripts of Znol4lb, whereas primer pair-2 does not recognize the shortest transcript (NM_001080652.1). The PCR amplified products with these primers showed near identical temporal expression pattern (Fig. 2B). The maternal expression of Znol4/b seen with primer pair-1 indicates the presence of the shortest transcript at this stage, as the primer pair-2 recognizing all other transcripts do not show maternal expression. Low level of Znol4lb expression can be detected up to 18 hours post fertilization (hpf). Increased expression of Znol4lb can be seen from 24 hpf onwards and remains constant until 72 hpf (Fig. 2B)

\section{Spatial expression pattern of Znol4lb}

Whole embryo mRNA in situ hybridization (WISH) was performed on different developmental stages of zebrafish embryos to study the spatial expression pattern of Znol4lb. Localized mRNA expression was detected from 12 hpf onwards. Znol4/b mRNA is localized to the intermediate mesoderm in 12 and $14 \mathrm{hpf}$ embryos (Fig. 3 B,C). Sixteen hpf embryos show strong expression in pronephric mesoderm (Gerlach and Wingert, 2013), the spinal cord (Lewis et al., 2003), trigeminal ganglia (Canger et al., 1998) and hind brain (Moens and Prince, 2002). Its expression in diencephalon and telencephalon also becomes visible (Fig. 3D). $Z n o l 4 / b$ is expressed in parts of fore brain such as diencephalon, telencephalon and epiphysis in $22 \mathrm{hpf}$ embryos. Its expression can be seen in tegmentum (Fig. 3E). It is also expressed in hind brain and the spinal cord. Znol4lb is expressed in the pronephric tubule, pronephric duct and proctodeum (Fig. 3E). The expression of Znol4lb in pronephric tubule and duct was confirmed by

Abbreviations used in this paper: NOL4L, nucleolar protein 4-like.

\footnotetext{
Accepted: 18 January 2016

ISSN: Online 1696-3547, Print 0214-6282

*Address correspondence to: Rajeeb K. Swain, Institute of Life Sciences, Nalco Square, Chandrasekhar Pur, Bhubaneswar, Odisha, India. Tel: +9167-4230-0137, Fax: +9167-4230-0728. E-mail: swain1900@ gmail.com - web: http://www.ils.res.in 
analyzing the expression of pronephric marker Zcdh17 (Fig. 3 F,F') (Wingert et al., 2007). Its expression in the ventral mesenchyme may represent the hematopoietic tissue (Fig. 3F').

This expression pattern of Znol4/b is maintained in $24 \mathrm{hpf} \mathrm{em-}$ bryos (Fig. 3 G-M"). The hind brain expression of Znol4lb starts at the midbrain hind brain boundary (MHB) region (Rhinn and Brand, 2001), but excluded from the boundary itself as concluded from two colour WISH analysis of MHB markers Zpax2a and Zpea3 (Fig. 3 H,I) (Pfeffer et al., 1998; Munchberg et al., 1999). A coronal section through the forebrain presents a better visualization of its expression (Fig. 3J). A transverse section through the trunk region provides clear visualization of Znol4/b in pronephros, gut and the spinal cord neurons (Fig. 3K). Znol4lb may also be expressed in the Rohon-Beard neurons as seen by its co-expression with Zpea3 (Fig. 3L) (Munchberg et al., 1999).

The dorsal view of a $24 \mathrm{hpf}$ embryo shows that, Znol4/b is strongly expressed in the hind brain and the spinal cord (Fig. 3M). A closer view confirms that Znol4/b is localized to the trigeminal ganglia (Fig. 3 M',M").

Both $27 \mathrm{hpf}$ and $30 \mathrm{hpf}$ embryos show strong expression of Znol4/bin diencephalon, telencephalon, epiphysis, tegmentum, trigeminal ganglia, hind brain and the spinal cord neurons (Fig. 3N,O). Expression of $Z$ nol $4 / \mathrm{b}$ is also visible in pronephros, proctodeum, the gut (Ober et al., 2003) and ventral mesenchyme, representing

A

\begin{tabular}{|c|c|}
\hline & -MPKPTLLLRGGWERERSPGDSELGRQFRDWCLRTYGDSAKTKTVTR \\
\hline Mmu & -MPKPTLLLRGGWERERSPGDSELGRQFRDWCLRTYGDSAKTKTVTRSKYQRIAEVLQGGGGTGAGSGPAAGEKGKFQFWVRSKGFRLGSGRE------PKMGQVVYVPVKTGSGADGI \\
\hline Dre_nol4lb & MSTKK-RVDLTRRSRSPAVSEAEMFGDFQEWCLRTYGDSGKTKTVTRRKYNKILQTLLQS DDSEGVI IESNH INAKFKFWVKSKGEQVGRSES--ENENGAADRPVLYVPI KA-TCVDGV \\
\hline Dre_nolula & MATKKPCADLTKRSRSPVVLEAEMFSEFQDWCLRTYGDSGKTKTVTRRKYNKIMQTLLQNEESDGVYVDNSHINAKFKFWVKSKGFQVGSNILGEHNKKESSGKPVLYVPVKS-TCSDGC \\
\hline & $---------M I D G V$ \\
\hline
\end{tabular}

HSa SEPEGISLKRVAVVEDFFDIIYSMHVESSAEPGKAPKHAGQKKTYRAIAETYAFLPREAV TRFLMSCTECQKRMHFNSNGLEPKENEPPSPLVSGIIDYNMPLTSTYLKOMKLRVMNSQ- 231 SEPEGISLKRVAVVEDFFDIIYSMHVESSAEPGKAPKHAGOKKTYRAIAETYAFLPREAV TRFLMSCTECQKRMHFNSSGPEPKENEPPSPLVSGIIDYNMPLTSTYLKOMKLRVMNSQ- 231 Dre nol4lb LGPDGSSLKRVAVVEDFYDIIYAMHVEISSDPAKAPKHAGQKKTYKAIAETYAFLPREAV TRFLMSCGECQKRMHISPSGAEFKENNQPSSLAADLIDYNMPLTTTYLKQKKLQCMNNN- 235 Dre nol4la TAQD-SSLKRVAVVEDFFDIIYAMHVEMGADPGRAPKHAGQKKTYKAIAETYAFLPREAV TRFLMSCGECQKRMHINPSTAEFKENDRPTSLVPDLIDYNMPLTATYLKQMKLQCMNTN- 237 Gga TAQD-SSLKRVAVVEDFFDIIYAMHVEMGADPGRAPKHAGQKKTYKAIAETYAFLPREAV TRFLMSCGECQKRMHINPSTAEFKENDRPTSLVPDLIDYNMPLTATYLKQMKLQCMNTN- 237
GVDEKLSLRRVAVVEDFFDIIYSMHVETGPNGEQIRKHAGQKRTYKAISETYAFLPREAV TRFLMSCSECQKRMHLNPDGADHKDNGKPPTLVTSMIDYNMPITMAYMKHMKLQLLNSQQ 125 GVDEKLSLRRVAVVEDFDIIYSMHVETGPNGEQIRKHAGQKRTYKAISETYAFLPREAV TRFLMSCSECQKRMHLNPDGADHKDNGKPPTLVTSMIDYNMPITMAYMKHMKLQLINSQQ 125
97 -MHVETGPNGEQIRKHAGQKRTYKAISETYAFLPREAV TRFLMSCSECQKRMHLNPDGGEHKDNGKPPTLVTSMIDYNMPITMAYMKHMKLQLINSQQ 97

Hsa EQDETSVSSEDFDMSDSTWMSADP--HLASSLSPSQ--DERMRSP-QNLHSQEDDDSSSE SGS-GNGSSTLNPST--------SSSTQGDPAFPEMNGNGAVAPMDFTTAAE------DQ 331 EODETSVSSEDFDMNDSAWMSADP--HLASSLSPSQ--EERMRSP-ONLHSOEDDDSSSE SGS-GNGSSTLNPST---_---_SSSTOGDPAFPEMNGNGAAAPMDFTATAE-----_-DQ 331 Dre_nol4la EQDESSVSSDLDMAEPAWVSTER-APAADPSSPAAPYTERMPTPPQPNIKEEEDDSSSENGSTANGLPALTPPGGAMATGGVPASEGVVPYGEVNGNGAAAPLDFSTSSSSSSQEGQQ 356 GgeGga xtr

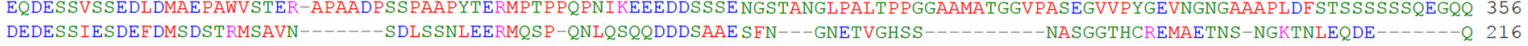
DEDESSIESDEFDMSDSTRMSAVN------SDLSSNLEERMQSP-QNLQGQQDDDSAAE SYT---CNETVGQAS--------NSTGATHNREMMEVITTNGNAISEQEE------ $Q 189$

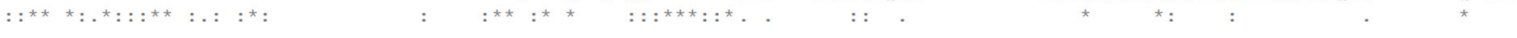

Hsa PINLCDKLPPATALGTAS------YPSDGCG--ADGLRSRVKYG---VKTTPESPPYSS GSYDSIKTEVSG-CPEDLTVGRAPTADDDDDDHDDHEDNDKMNDSEGMDPERLKAFNMFV 438 PINLCDKLPATALGTS-_ Y

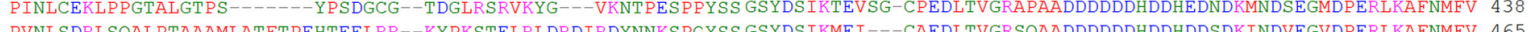

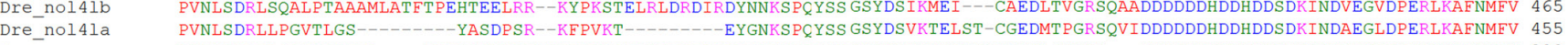
PLNLSDSPLSAQLTSEYR----LDDHSSNGKNKYKTLIISDLKMEREARENGSKSPAHSY SSYDSGKNESVDRGAEDLSLNRG---DEDEDDHDEQEDPEKVNESDGVEAERLKAFNMFV 329 Xtr PLNLSDCPVSSQLNPEYR---IDDHSSNGKHPYKNLLIGDLKMDREARENGNKSPAHSY SSYDSGKNESVGGCGEDLSMTRG---DEDEDDHDDHEDAEKAAESDGVEAERLKAFNMFV 302

RLFVDENLDRMVISKQPKEKIQAIIESCSRQFPEFQERARKRIRTYLK 3CRRMKKNGMEMTRPTPPHLTSAMAENILAAACESETRKAAKRMRLEIYQSSQDEPIALDKQHSRDSAAIT 558 RI FVDENTDRMVPT $\begin{array}{ll}\text { Dre_nol4la } & \text { RLFVDENLDRMVPISKQPKEKIQAIIESCSRQFPEFQERSRKRIRTYLSCRRMKKGGEE-SRPTPPHLTSAMAENILAAACESETRNAAKRMRLDIYQ-AHDESTTADKPNSRDPAALA } 573 \\ \text { Gga } & \text { RLFVDENLDRMVPISKOPKEKIOAIIDSCRROFPEYQERARKRIRTYLKSCRRMKRSGFEMSRPIPSHLTSAVAESILASACESESRNAAKRMRLDROQ---DEATPADKOYKOEPAOVT } 446\end{array}$ $\begin{array}{ll}\text { Gga } & \text { RLFVDENLDRMVPISKQPKEKIQAIIDSCRRQFPEYQERARKRIRTYLKSCRRMKRSGFEMSRPIPSHLTSAVAESILASACESESRNAAKRMRLDRQQ---DEATPADKQYKQEPAQVT } 446 \\ \mathrm{Xtr} & \text { RLFVDENLDRMVPISKQPKEKIQAIIDSCRRQFPEYQERARKRIRTYLKSCRRMKRSGEEMSRPIPSHLTSAVAETILASACESESRNAAKRMRLDRQ----DETPPADKSHKQDTAQVT } 418\end{array}$ DETPPADKSHKQDTAQVT 418

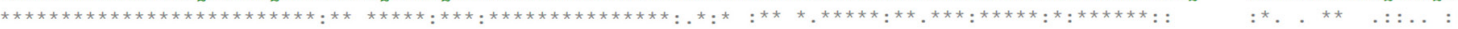

\section{Hsa Mre nol 1 lib Dre_nolula Gga xtr}

$\begin{array}{lll}\text { Hsa } & \text { AGYRESAAFLLRSADELENLILQQN } & 680 \\ \text { Mmu } & \text { AGYRESAAFLLRSADELENLILQQN } & 679 \\ \text { Dre_nol4lb } & \text { AGYRESAAFLLRSADELENLILQQN } & 704 \\ \text { Dre_noI4la } & \text { AGYRESAAFLLRSADELENLILQQN } & 691 \\ \text { Gga } & \text { AGYRESAAFLLRSADELENLILQQN } & 579 \\ \text { Xtr } & \text { AGYRESAAFLLRSADELENLILQQN } & 524\end{array}$

Fig. 1. Alignment of NOL4L protein sequences. (A) The longest form of the protein from Homo sapiens (Hsa), Mus musculus (Mmu), Gallus gallus (Gga), Xenopus tropicalis (Xtr) and Danio rerio (Dre) were aligned using ClustalW2. (B) Percent identity matrix showing high degree of conservation of NOL4L among these species. (C) The phylogenetic tree.
-NGPTDISMKGGASTTSTTPTTPTPSSTSTSRPVPTAOTSPTETSAVROLI 655 -NGPTDLSMKGGASTP-TPPTPTPSSNSTSRTMPTAQLSPTEISAVRQLI 654

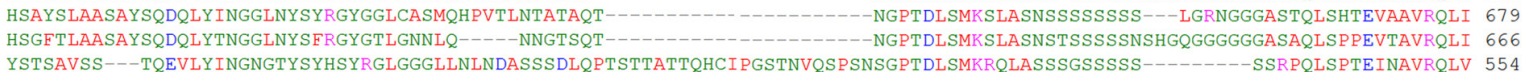

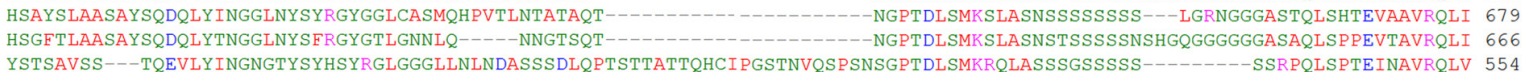
YSTSAVSS---TQEVLYINGNGTYSYHSYRGLGGGLLNLNDASSSDLQPTSTTATTQHCIPGSTNVQSPSNSGPTDLSMKRQLASSSGSSSSS---------SSRPQLSPTEINAVRQLV 554 YSTSAVSS---TQDVLYINGNGTYSYHTYRGLGGGLLNLSDTS---

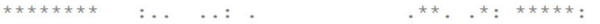

B

\begin{tabular}{|c|c|c|c|c|c|c|}
\hline & Hsa & Mmu & $\begin{array}{c}\text { Dre } \\
\text { nol4lb }\end{array}$ & $\begin{array}{c}\text { Dre } \\
\text { nol4la }\end{array}$ & Gga & Xtr \\
\hline $\begin{array}{c}\text { Hsa- } \\
\text { NP_001243727.1 }\end{array}$ & 100.00 & 96.32 & 62.95 & 62.59 & 57.17 & 57.73 \\
\hline $\begin{array}{c}\text { Mmu- } \\
\text { NP_001127772.1 }\end{array}$ & 96.32 & 100.00 & 62.74 & 62.84 & 56.35 & 57.06 \\
\hline $\begin{array}{c}\text { Dre_nol4lb- } \\
\text { XP_009295020.1 }\end{array}$ & 62.95 & 62.74 & 100.00 & 74.19 & 56.47 & 56.12 \\
\hline $\begin{array}{c}\text { Dre_nol4la- } \\
\text { XP_001922545.4 }\end{array}$ & 62.59 & 62.84 & 74.19 & 100.00 & 56.02 & 56.11 \\
\hline $\begin{array}{c}\text { Gga- } \\
\text { XP_004939884.1 }\end{array}$ & 57.17 & 56.35 & 56.47 & 56.02 & 100.00 & 87.76 \\
\hline $\begin{array}{c}\text { Xtr- } \\
\text { XP_002934174.2 }\end{array}$ & 57.73 & 57.06 & 56.12 & 56.11 & 87.76 & 100.00 \\
\hline
\end{tabular}

C

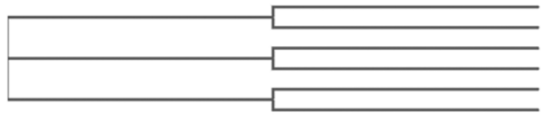
Hsa 0.01724
Mmu 0.01958 Dre_nol4lb 0.12817 Dre_nol4la 0.12994 Gga 0.06245 Xtr 0.05992 
A

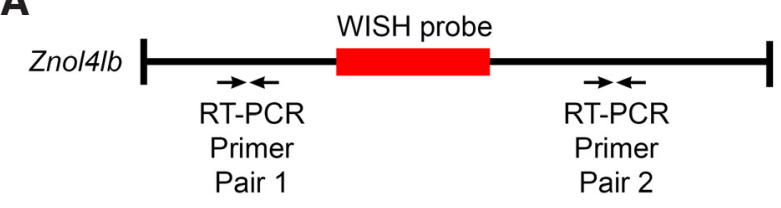

B

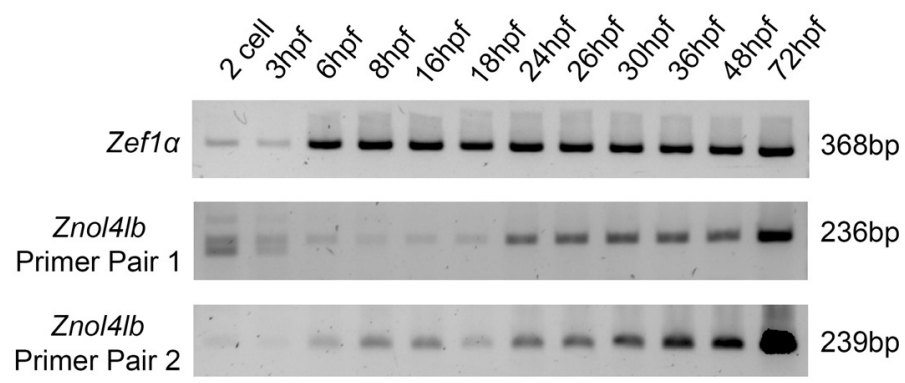

Fig. 2. Temporal expression of zebrafish nol4lb (Znol4lb) mRNA. (A) Schematic representation of Znol4lb and position of two sets of primers used in RT-PCR and the probe used for WISH. (B) Expression of Znol4lb $m R N A$ during zebrafish development. Zef1 $\alpha$ is used as a loading control.

caudal hematopoietic tissue (Fig. 3N) (Jing and Zon, 2011). Two colour WISH of Znol4lb and Zcdh17 confirms the expression of this gene in pronephric tubule and duct. Znol4lb is expressed in the gut, which lies ventral to the Zcdh17 expression domain (Fig. 3 O,O'). Similarly, Znol4lb is seen outside the Zcdh17 expression domain on the dorsal side, presumably in the hematopoietic territory (Fig. 30'). A higher magnification picture of the trunk region of a $72 \mathrm{hpf}$ embryo shows that, Znol4lb is expressed both in the pronephric tubule, pronephric duct and the gut (Fig. 3P).

Here, we have described the temporal and spatial expression pattern of Znol $4 / b$ during zebrafish embryogenesis. It is expressed in the central nervous system, pronephric tubule, pronephric duct,
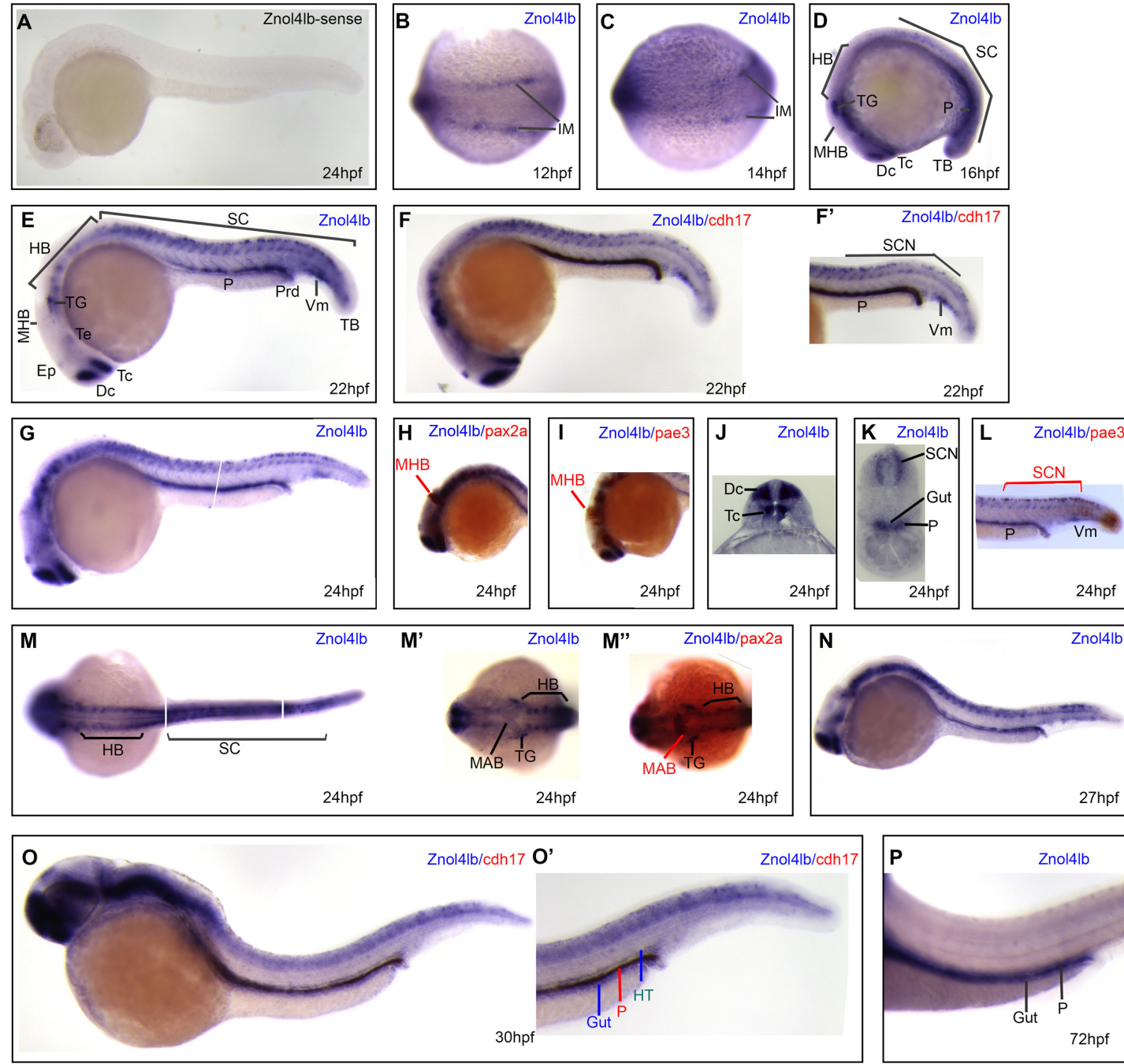

(2)
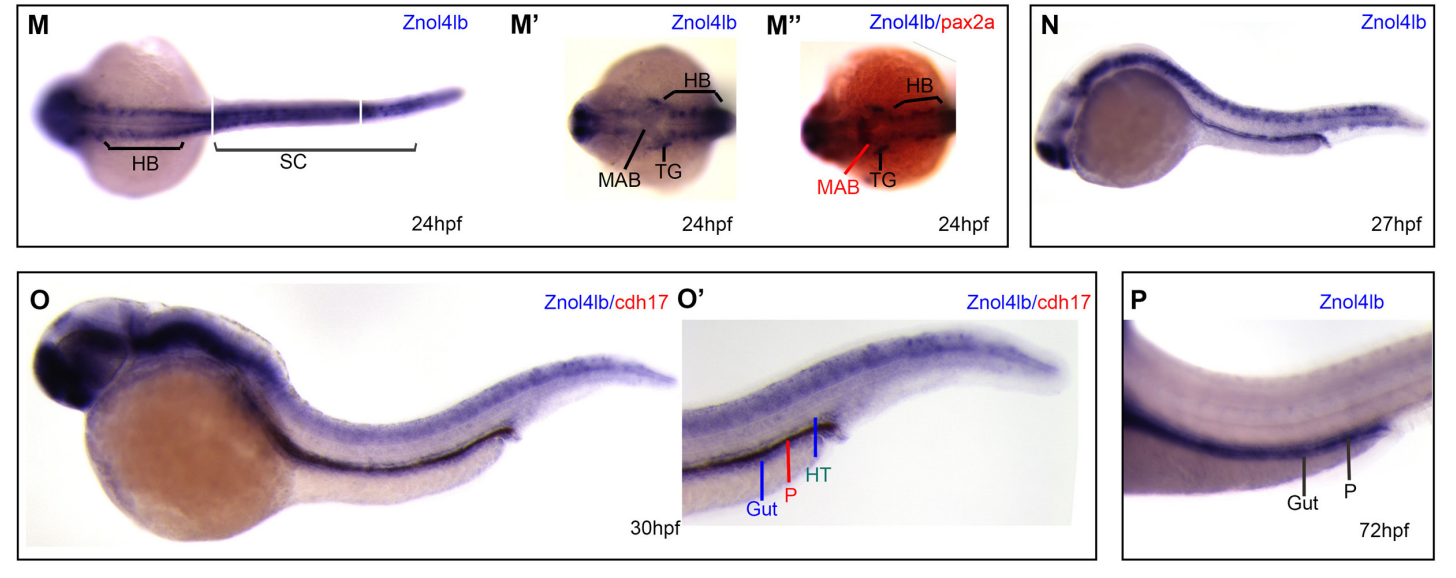
brain and spinal cord. (M') Higher magnification picture showing Znol4lb expression in the trigemina ganglia. (M") Two colour WISH with Zpax2a shows that, Znol4lb is not expressed in the midbrain-hind brain boundary (MHB). (N) Expression of Znol4lb at 27 hpf. (O) 30 hpf embryo showing overlapping

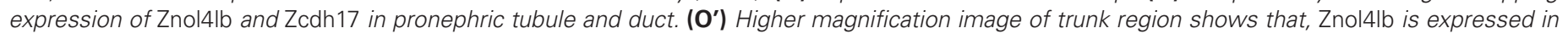
pronephros (P), the gut and the hematopoietic territory (HT). (P) Znol4lb is expressed in pronephros and the gut at $72 \mathrm{hpf}$.

Fig. 3. Spatial expression pattern on Znol4lb mRNA. Whole embryo mRNA in situ hybridization (WISH) on wild type embryos was carried out from 12 hpf to 72 hpf. (A) DIGlabeled sense probe shows no background staining. Znolulb expression in intermediate mesoderm at 12 (B) and $14 \mathrm{hpf}$ (C). (D) Expression of Znol4lb in telencephalon (TC), diencephaIon (DC), trigeminal ganglia (TG), hind brain (HB), spinal cord (SC), pronephric mesoderm $(P)$ and tail bud (TB) at $16 \mathrm{hpf}$ (E) At 22 hpf, Znol4lb is expressed in telencephalon, diencephalon, epiphysis (Ep), Tegmentum (Te), trigeminal ganglia, hind brain, spinal cord, pronephric tubule and duct $(P)$, proctodeum (Prd) and ventral mesenchyme (Vm). $\left(\mathbf{F}, \mathbf{F}^{\prime}\right)$ Coexpression of Znol4lb and Zcdh17 in the pronephric tubule and duct. (G) 24 hpfembryo showing expression domains of Znol4lb. Two colourWISH showing expression of Znol4lb and Zpax2a (H) and Zpea3 (I) in the head. (J) Section through forebrain. (K) Section through the trunk showing Znol4lb expression in pronephros $(P)$, gut and spinal cord neurons (SCN). (L) Znol4lb is expressed with Zpea3 in SCN. (M) Dorsal view of a 24 hpf zebrafish embryo showing Znolulb expression in the hind pf. 
and the gut and at low levels in the hematopoietic cells. This complex expression pattern underpins the important functions this gene may have during zebrafish development. The human ortholog of this gene is implicated in leukemia. It would be interesting to study the function of this gene in the embryonic and adult hematopoietic system in zebrafish. Genetic and functional characterization of Znol4lb will clarify its function during zebrafish development and would provide clues for understanding its function in other vertebrates including humans.

\section{Materials and Methods}

\section{Cloning of Znol4lb}

Total RNA was extracted from $24 \mathrm{hpf}$ zebrafish embryos using TriZol reagent (Invitrogen) following manufacturer's instructions. cDNA was synthesized using SuperScript-III cDNA synthesis kit (Invitrogen). The Znol4lb was amplified by PCR (forward 5'-CAATCTCTAAACAGCCTAAAGAGAAGA-3', reverse 5'-TAGCTAAAAACAAAGAACATGAGGAAT-3', $\mathrm{Tm} 60^{\circ} \mathrm{C}, 35$ cycles). The amplified fragment was cloned into pCR-BluntllTOPO vector (Invitrogen) and sequenced.

\section{$R T-P C R$}

Total RNA was extracted from zebrafish embryos of various developmental stages as described above and cDNA was prepared using equal amounts of RNA. Two pair of PCR primers was designed using Primer-3 for checking the expression of Znol4/b. The primers and PCR conditions were as follows: Primer pair-1 (forward 5'-GTGTTCAGTGAGTAGCGAGGAGT-3', reverse 5'-GTCCAGTACTGTCATTCACACCA-3', Tm 55' $\mathrm{C}, 30$ cycles) and primer pair-2 (forward 5'-TTCGCAGATGCCAACACTCT-3', reverse 5' -TGGTTGTGTTTGGGAGGCTT3', Tm $55^{\circ} \mathrm{C}, 30$ cycles). Zebrafish ef1 $\alpha$ (forward 5'-CTTCTCAGGCTGACTGTGC-3', reverse 5'-CCGCTAGCATTACCCTCC $-3,{ }^{\prime}, \operatorname{Tm} 55^{\circ} \mathrm{C}, 22$ cycles) was used as a loading control.

\section{Zebrafish whole embryo in situ hybridization (WISH) and histology}

Wild type zebrafish strains, Tübingen and Albino were used in all experiments. The embryos were staged according to Kimmel et al., 1995. WISH experiments were carried out following previously described protocols (Thisse and Thisse, 2008). Digoxigenin or Fluorescein labeled antisense probes was synthesized by linearizing the plasmids and transcribing with T7 polymerases (Znol4/b linearized with Kpnl, Zpax2a linearized with Sacll, Zcdh17 linearized with BamHI, Zpea3 linearized with Notl). The sense probe for Znol4lb was synthesized by linearizing the plasmid with Xbal and transcribing with SP6 polymerase. BM-purple and INTBCIP (Roche) were used as chromogenic substrates in WISH. Pictures were taken using Leica MZ16 stereo microscope. Vibratom sections were prepared from gelatin embedded embryos after WISH.

\section{Acknowledgements}

We thank Herbert Steinbeisser for Zpea3 plasmid, Kirsten Linsmeier for zebrafish histology, Mahendra Sonawane for support and Chetana Sachidanandan for comments on Znol4lb expression pattern. We thank Jaisen Mahankuda for technical help and Pranita Rout for maintaining zebrafish facility. RKS is a recipient of Department of Biotechnology (DBT) Ramalingaswami fellowship and SB and PB are recipients of DBT-SRF. This work was supported by intramural funds from ILS, which is an autonomous institute of DBT, Government of India.

\section{References}

AN, Q., WRIGHT, S. L., KONN, Z. J., MATHESON, E., MINTO, L., MOORMAN, A. V., PARKER, H., GRIFFITHS, M., ROSS, F. M., DAVIES, T., HALL, A. G., HARRISON, C. J., IRVING, J. A., and STREFFORD, J. C. (2008). Variable breakpoints target PAX5 in patients with dicentric chromosomes: a model for the basis of unbalanced translocations in cancer. Proc Natl Acad Sci U S A 105: 17050-17054.

CANGER, A. K., PASSINI, M. A., ASCH, W. S., LEAKE, D., ZAFONTE, B. T., GLASGOW, E., and SCHECHTER, N. (1998). Restricted expression of the neuronal intermediate filament protein plasticin during zebrafish development. J. Comp. Neurol. 399: 56157.

GERLACH, G. F., and WINGERT, R. A. (2013). Kidney organogenesis in the zebrafish: insights into vertebrate nephrogenesis and regeneration. Dev. Biol. 2: 559-585.

GUASTADISEGNI, M. C., LONOCE, A., IMPERA, L., DI TERLIZZI, F., FUGAZZA, G., ALIANO, S., GRASSO, R., CLUZEAU, T., RAYNAUD, S., ROCCHI, M., and STORLAZZI, C. T. (2010). CBFA2T2 and C20orf112: two novel fusion partners of RUNX1 in acute myeloid leukemia. Leukemia 24: 1516-1519.

JING, L., and ZON, L. I. (2011). Zebrafish as a model for normal and malignant hematopoiesis. Disease Models Mech 4: 433-438.

KAWAMATA, N., OGAWA, S., ZIMMERMANN, M., NIEBUHR, B., STOCKING, C., SANADA, M., HEMMINKI, K., YAMATOMO, G., NANNYA, Y., KOEHLER, R., FLOHR, T., MILLER, C. W., HARBOTT, J., LUDWIG, W. D., STANULLA, M., SCHRAPPE, M., BARTRAM, C. R., and KOEFFLER, H. P. (2008). Cloning of genes involved in chromosomal translocations by high-resolution single nucleotide polymorphism genomic microarray. Proc Natl Acad Sci USA 105: 11921-11926.

KIMMEL, C. B., BALLARD, W. W., KIMMEL, S. R., ULLMANN, B., and SCHILLING, T. F. (1995). Stages of embryonic development of the zebrafish. Dev. Dynam. 203: 253-310.

LEWIS, K. E., and EISEN, J. S. (2003). From cells to circuits: development of the zebrafish spinal cord. Prog. Neurobiol. 69: 419-449.

MOENS, C. B., and PRINCE, V. E. (2002). Constructing the hindbrain: insights from the zebrafish. Dev. Dynam. 224: 1-17.

MUNCHBERG, S. R., OBER, E. A., and STEINBEISSER, H. (1999). Expression of the Ets transcription factors erm and pea3 in early zebrafish development. Mech Dev. 88: 233-236.

OBER, E. A., FIELD, H. A., and STAINIER, D. Y. (2003). From endoderm formation to liver and pancreas development in zebrafish. Mech. Dev. 120: 5-18.

PFEFFER, P. L., GERSTER, T., LUN, K., BRAND, M., and BUSSLINGER, M. (1998). Characterization of three novel members of the zebrafish Pax2/5/8 family: dependency of Pax5 and Pax8 expression on the Pax2.1 (noi) function. Development 125: 3063-3074.

RHINN, M., and BRAND, M. (2001). The midbrain--hindbrain boundary organizer. Current opinion in neurobiology 11, 34-42.

THISSE, C., and THISSE, B. (2008). High-resolution in situ hybridization to wholemount zebrafish embryos. Nature Protocols 3: 59-69.

WINGERT, R. A., SELLECK, R., YU, J., SONG, H. D., CHEN, Z., SONG, A., ZHOU, Y., THISSE, B., THISSE, C., MCMAHON, A. P., and DAVIDSON, A. J. (2007). The cdx genes and retinoic acid control the positioning and segmentation of the zebrafish pronephros. PLoS genetics 3: 1922-1938. 


\section{Further Related Reading, published previously in the Int. J. Dev. Biol.}

Identification of distal enhancers for Six2 expression in pronephros

Nanoka Suzuki, Kodai Hirano, Hajime Ogino and Haruki Ochi

Int. J. Dev. Biol. (2015) 59: 241-246

Expression of protocadherin-19 in the nervous system of the embryonic zebrafish Qin Liu, Yun Chen, Fumitaka Kubota, Jean J. Pan and Tohru Murakami Int. J. Dev. Biol. (2010) 54: 905-911

Expression of protocadherin 18 in the CNS and pharyngeal arches of zebrafish embryos Fumitaka Kubota, Tohru Murakami, Yuki Tajika and Hiroshi Yorifuji Int. J. Dev. Biol. (2008) 52: 397-405

Expression dynamics of the LIM-homeobox genes, Lhx1 and Lhx9, in the diencephalon during chick development

Xiangnan Sun, Hirotomo Saitsu, Kohei Shiota and Makoto Ishibashi Int. J. Dev. Biol. (2008) 52: 33-41

Cadherin-6 is required for zebrafish nephrogenesis during early development Fumitaka Kubota, Tohru Murakami, Kenji Mogi and Hiroshi Yorifuji Int. J. Dev. Biol. (2007) 51: 123-129

5 yr ISI Impact Factor $(2013)=2.879$

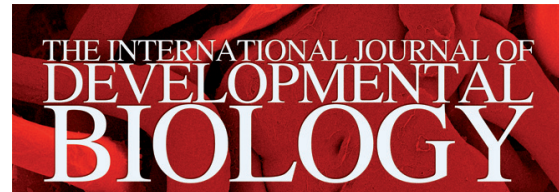

Volume 57 Nos. 2/3/4

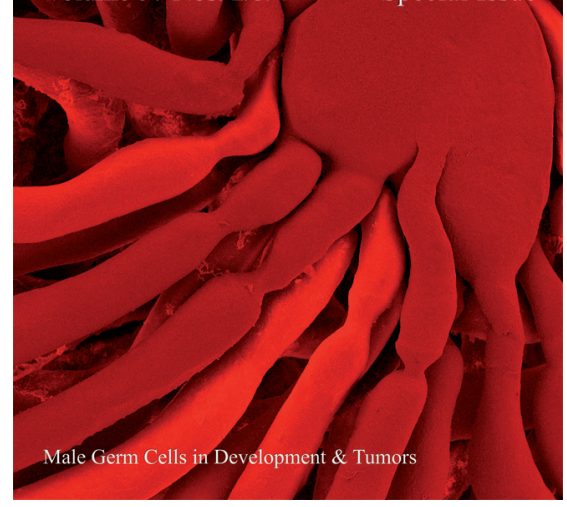

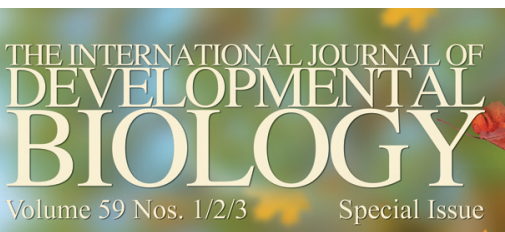

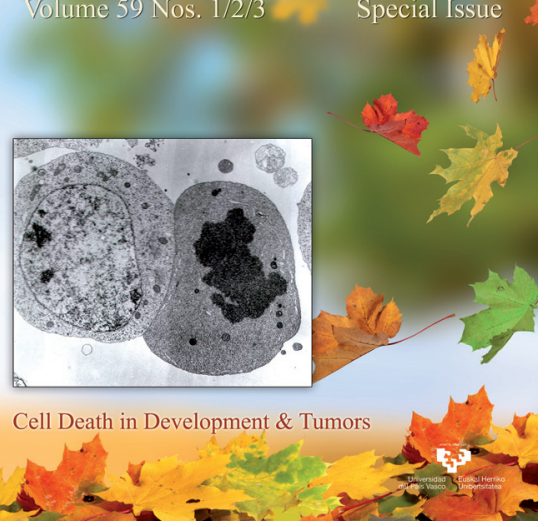

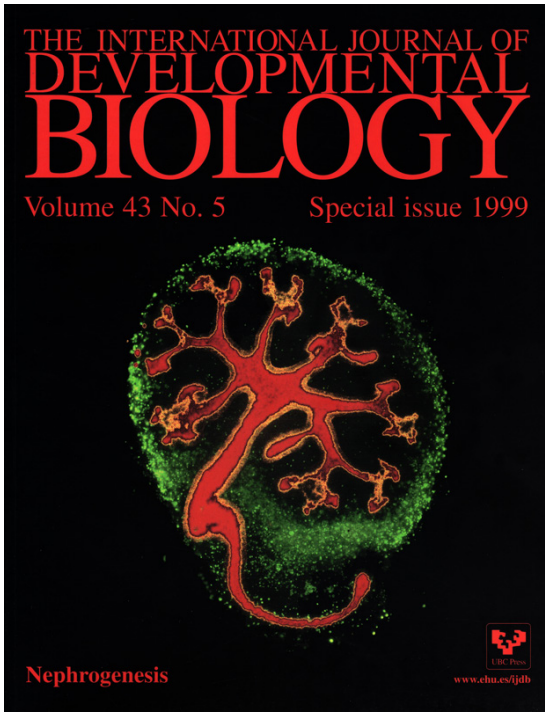

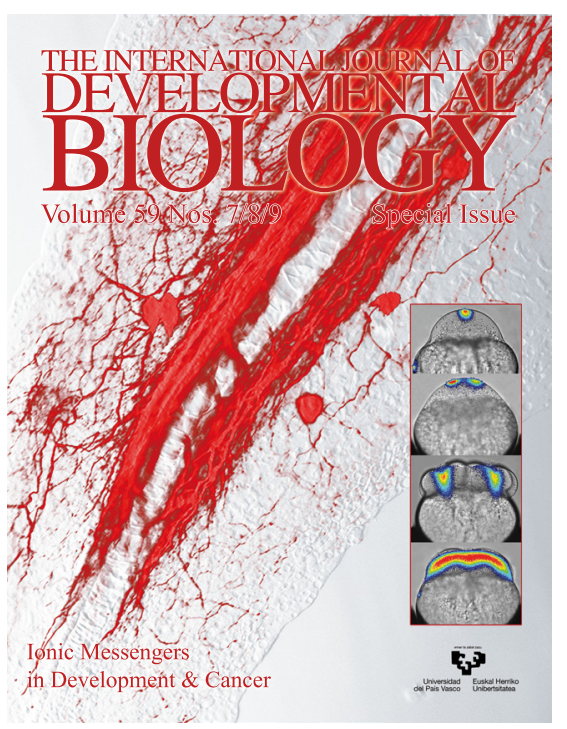

